\title{
Sustainable geoscience
}

To the Editor - Humankind is using more natural resources than ever before. The way we are using these materials has already started to irreversibly affect our ecosystem. Overuse of the Earth's natural wealth has the potential to impact on our ability to sustain the economy, safeguard national security and maintain the natural environment. Geoscientists are well placed to make critical contributions to contemporary sustainability issues. Yet, most geologists have little or no direct involvement in the growing societal shift towards sustainable development.

Humans are now a dominant geological force on the planet. The cumulative impacts of anthropogenic changes are sufficiently significant to earn their own bespoke epoch: the Anthropocene. In this burgeoning human age, the applied aspects of economic geology, petroleum geology, engineering geology, hydrogeology and geohazards assume even greater importance, alongside climate science, land management and disaster risk reduction. It is surprising then that today we geologists find ourselves woefully underrepresented in relation to other disciplines in current discourses on Earth's health and well-being ${ }^{1}$.

Geologists possess a valuable synoptic and temporal conceptual framework for evaluating Earth's sustained viability for life. We are trained in a range of practical skills and offer flexible mindsets - characteristics that are well suited to developing more sustainable environmental practices ${ }^{1}$. As a community, we must get more involved in the sustainable development arena by broadening our experiences and explicitly integrating sustainability into geoscience education and training.

It is clear that geoscientists need to work with engineers and planners, but we must be more ambitious than this. We must collaborate with allied Earth science disciplines such as biology, zoology, ecology, agronomy and environmental science. More significantly, to fully appreciate the complexity of contemporary humanenvironment relations, we must also draw from the social sciences.

The key role of social science disciplines is arguably most critical in enhancing our ability to communicate our geoscientific know-how to those lay audiences that we feel most need it, whether policymakers, civic authorities, business leaders, the media or the public at large. Those areas of geoscience that are at the front line of societal engagement - most acutely in the fields of climate change and natural hazards - appreciate all too readily that simply explaining the technical science rarely effects meaningful mitigative actions among those at risk $^{2}$. Indeed, an important paradox of geoscience communication is that the more effectively a potential threat is made public by the scientist, the more readily the scientific message becomes normalized into the complex and chaotic discourses of daily life. Scientific concerns become subsumed and are lost within wider social, economic and political concerns ${ }^{3}$.

\section{To fully appreciate the complexity of contemporary human-environment relations, we must also draw from the social sciences.}

For decades, social scientists have recognized this dilemma and have developed methodologies and strategies for deconvolving public attitudes, motivations and perceptions about scientific problems. If geoscientists are going to contribute effectively to sustainability issues then we will need to quickly grasp practical ways to overcome such formidable societal asperities. There are signs that some geologists are trying to do just that, especially in the societal front line of natural hazards. In the UK, for example, the Natural Environment Research Council is currently funding innovative interdisciplinary research projects including Strengthening Resilience in Volcanic Areas (http:// streva.ac.uk/) and Earthquakes without Frontiers (http://ewf.nerc.ac.uk/) in which geoscientists work alongside social scientists to identify and address generic issues in disaster risk.

Away from its immediate public interface, however, geology remains a realm that most people pay little attention to and show little interest in ${ }^{4}$. Few have anything but a vague and often misconceived sense of the subsurface, an alien environment that lies hidden and out of bounds. Moreover, most struggle to grasp the cumulative impact of slow, gradual changes over periods that exceed human time spans, or appreciate the feedbacks lurking within complex natural systems. This unfamiliarity with geoscience is understandable given that most countries lack a direct exposure to geology within the school curriculum ${ }^{4}$. Until recently, there was little incentive among academics and industry professionals to help bridge that divide and translate our science for non-technical audiences. In the past few years, however, this longstanding science-public disconnect has been countered as national governments, funding agencies and institutions demand greater public accountability for research through increased outreach activity. With geoscientists now expected to justify what we are doing and why we are doing it, the impetus to convey geological relevance to sustainable development will only increase.

Sustainable geoscience - and how to communicate it - must become integrated into geological education and professional development ${ }^{5}$. Teaching geology students to work with other scientists, business people and politicians to develop viable solutions to environmental and resource challenges is likely to significantly increase their employability. Moreover, stronger academic engagement with local environmental issues will bring community-based stakeholders, including employers, into the classroom ${ }^{5}$. Students who think that geology is simply the study of rocks will appreciate that it is really about how the Earth works and what that means for those living on it. And geology always has been about that. In 1788, James Hutton's seminal work, Theory of the Earth, opened with the remark that "this globe of the earth is a habitable world, and on its fitness for this purpose, our sense of wisdom in its formation must depend"6. Almost 250 years on, geologists are still struggling to put that vision into practice.

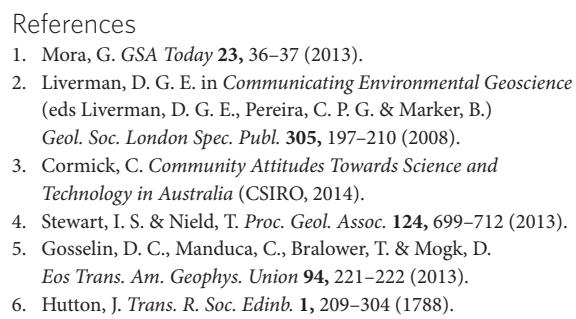

\section{lain Stewart}

Sustainable Earth Institute,

Plymouth University, Plymouth PL4 8AA, UK.

e-mail: iain.stewart@plymouth.ac.uk 